Park Bumsoo (Orcid ID: 0000-0003-4505-2368)

\title{
Association of midline prostatic cysts and lower urinary tract symptoms: a case-control analysis of 606 transrectal ultrasound findings
}

Running Title: Midline prostatic cysts and symptoms

\author{
Bumsoo Park, MD, PhD, ${ }^{1}$ Sung-Ho Ju, MD, ${ }^{2}$ Seol Ho Choo, MD, $\mathrm{PhD}^{3^{*}}$ \\ ${ }^{1}$ Departments of Family Medicine and Urology, University of Michigan Medical School, Ann \\ Arbor, Michigan, USA \\ ${ }^{2}$ Department of Urology, Kangnam General Hospital, Yongin, South Korea \\ ${ }^{3}$ Department of Urology, Ajou University School of Medicine, Suwon, South Korea
}

*Correspondence to: Dr. Seol Ho Choo, Department of Urology, Ajou University School of Medicine, 164 World Cup-ro, Yeongtong-gu, Suwon 443-380, Gyeonggi-do, South Korea.

Tel: +82-31-219-7845

FAX: +82-31-219-5276

E-mail: predoc2@gmail.com

This is the author manuscript accepted for publication and has undergone full peer review but has not been through the copyediting, typesetting, pagination and proofreading process, which may lead to differences between this version and the Version of Record. Please cite this article as doi: $10.1111 /$ luts.12288

This article is protected by copyright. All rights reserved. 


\begin{abstract}
OBJECTIVE: To evaluate the association between midline prostatic cysts (MPCs) and lower urinary tract symptoms (LUTS).
\end{abstract}

METHODS: A total of 606 patients who underwent transrectal ultrasound of the prostate (TRUS) were retrospectively reviewed. Patients were divided into two groups based on the presence of MPCs for comparison. We used the International Prostate Symptoms Score (IPSS) as a LUTS parameter. Multivariate analysis was performed to find out independent predictors for moderate to severe LUTS. An MPC subgroup analysis was done to look for linear correlation between the size of MPCs and LUTS.

RESULTS: Patients with no MPCs had higher age, more history of diabetes, more taking urological medications, and more storage IPSS symptoms. No significant differences were found in body mass index, total IPSS, voiding IPSS, bother score, total prostate-specific antigen level, and the prostate size. Multivariate analysis revealed age, history of diabetes, taking urological medications, and the prostate size as independent predictors of moderate to severe LUTS. The presence of MPCs was not an independent factor. Subgroup analysis failed to show significant correlation between the size of MPCs and the LUTS scores.

CONCLUSIONS: The presence of MPCs was not an independent factor for moderate to severe LUTS, and the size of the MPCs also did not have correlation to LUTS score. 
KEY WORDS: Cysts, Lower Urinary Tract Symptoms, Prostatic neoplasms, Urination

\section{INTRODUCTION}

A midline prostatic cyst (MPC) is a cystic lesion found in the midline area of the prostate, which is commonly detected on transrectal ultrasound of the prostate (TRUS) in urologic clinical settings. It has been reported that $7.6 \%$ of asymptomatic patients, and $5 \%$ of patients with urological symptoms, have MPCs. ${ }^{1,2}$ Traditionally, MPCs have been classified as Müllerian duct cyst, prostatic utricle cyst, ejaculatory duct cyst, prostatic retention cyst, or cystic dilatation of the utricle, but still there is no standardized classification system, and it remains controversial. ${ }^{3-7}$ Even though the above classification can be anatomically clear, it is rarely pertinent to actual clinical practice, and is hard to differentiate among above classification with imaging studies. Recently, efforts have been made to simplify the classification system. Furuya et al. classified MPCs into four categories: Type 1 (MPC with no communication into the urethra), Type 2a (MPC with communication into the urethra), Type 2b (cystic dilatation of the prostatic utricle with communication into the seminal tract), and Type 3 (cystic dilatation of the ejaculatory duct). ${ }^{6}$ Shebel et al. classified prostatic cysts into three categories: median cysts (prostatic utricle cysts, Müllerian duct cysts), paramedian cysts (ejaculatory duct cysts), and lateral cysts (prostatic 
retention cysts, cystic degeneration of benign prostatic hyperplasia, cysts associated with tumors, prostatic abscess). ${ }^{7}$

It has been generally known that MPCs do not cause LUTS, but there have been several case reports that suggest MPCs led to LUTS ${ }^{8-12}$ Furthermore, a few studies have even shown that a significant number of patients with MPCs showed urological symptoms. ${ }^{1,13}$ Even though MPCs are one of the common abnormalities on TRUS, there have been no well-established studies so far, and there has been clinical dilemma especially when urologists explain the findings of MPCs to patients in routine practice. Therefore, we conducted this study to evaluate if MPCs are associated with LUTS. 


\section{METHODS}

\section{Study Design and Patient Population}

We retrospectively reviewed and analyzed the medical records of 606 patients who received TRUS between October 2013 and March 2015. Enrolled patients for this study consisted of new outpatient urology patients presenting with LUTS, or those examined at the Health Screening Center for routine health maintenance at Kangnam General Hospital, per the hospital's health screening policy. Patients who underwent TRUS for follow-up purpose were excluded. If a

This article is protected by copyright. All rights reserved. 
patient underwent two or more TRUS's, only the initial TRUS was chosen for the study. Patients were divided into two groups according to the presence of MPCs on TRUS.

\section{Variables}

In each group, variables such as age, history of diabetes mellitus (DM) (which can potentially affect LUTS), concurrent urological medications (defined as alpha-blockers, 5-alpha reductase inhibitors, and/or antimuscarinics), body mass index (BMI), international prostatic symptom score (IPSS) with bother score, prostate-specific antigen (PSA) levels, and TRUS findings (MPCs, prostate size) were collected. If MPCs were detected during the TRUS exam, transverse diameter was measured. In this study, MPCs were defined as any low echoic or anechoic smooth-surfaced cystic lesion located in the midline of the prostate on the axial TRUS image. Examples of variable-sized MPCs are demonstrated in Figure 1. A single urologist (BP) performed all TRUS procedures and measured the size of the MPCs.

\section{Outcome Measures}

To address LUTS, IPSS with bother score was used as a tool. "Storage IPSS” was defined as the sum of items 2, 4, and 7, while "voiding IPSS" was defined as the sum of items 1, 3, 5, and 6. “Mild LUTS” was defined as IPSS $\leq 7$, while "moderate/severe LUTS” was defined as IPSS $\geq$ 8, based on the American Urological Association Measurement Committee. ${ }^{14}$ 


\section{Statistical Analysis}

We used independent t-test, chi-square test, and Fisher's exact test to compare the distribution of clinical variables across the presence of MPCs. For univariate and multivariate analysis to determine independent predictors for moderate/severe LUTS, the binary logistic regression test was used. We set the moderate/severe LUTS as the multivariate analysis endpoint because guidelines generally recommend to start pharmacologic treatment for moderate/severe LUTS. ${ }^{15,16}$ Step-wise regression techniques were used to build multivariate models using a significance level of 0.15 for the covariate to remain in the model. Some covariates with no significance on univariate analysis were also included in the model if the authors were interested in investigating their association with LUTS. On the other hand, we performed a subgroup analysis to find out whether the size of the MPCs may affect LUTS within the MPC group. The partial correlation test was conducted to evaluate a linear correlation between the size of the MPCs and each element of IPSS questionnaire (total IPSS, storage IPSS, voiding IPSS, and bother score), while adjusting age, history of DM, concurrent urological medications, and prostate size that might act as confounders. All analyses were performed using PASW Statistics 18 (SPSS Inc., Chicago, IL, USA), and a $P$ value $<0.05$ was considered statistically significant.

\section{Ethics Statement}

The study protocol was approved by the Institutional Review Board of Ajou University Hospital (IRB File No. AJIRB-MED-MDB-15-052). Ajou University Hospital has an educational 
affiliation with Kangnam General Hospital. Informed consent was waived by the board.

This article is protected by copyright. All rights reserved. 


\section{RESULTS}

MPCs of any size were present in 199 (32.8\%) of the 606 participants. Age (58.92 vs 56.69 years, $p=0.038)$, patients with a history of DM (87 vs 26; $\mathrm{p}=0.014)$, patients who are on concurrent urological medications (53 vs 12; $\mathrm{p}=0.008$ ), and storage IPSS (5.60 vs 4.80, $p=$ 0.016) were significantly higher in the no MPC group than the MPC group. No significant differences in BMI, total IPSS, voiding IPSS, bother score, total PSA, or prostate size were observed between the groups (Table 1). A multivariate analysis showed that age (odds ratio [OR], 1.040; 95\% confidence interval [CI], 1.022-1.058), history of DM (OR, 1.887; 95\% CI, 1.0573.368), concurrent urological medications (OR, 3.386; 95\% CI, 1.298-8.833), and prostate size (OR, 1.029; 95\% CI, 1.004-1.055) significantly predicted moderate/severe LUTS. However, the presence of MPC was not an independent predictor of moderate/severe LUTS (Table 2). The MPC subgroup analysis failed to reveal any linear correlation between the size of MPCs and total IPSS $(r=0.010)$, storage IPSS $(r=-0.061)$, voiding IPSS $(r=0.049)$, or bother score $(r=$ 0.106).

This article is protected by copyright. All rights reserved. 


\section{DISCUSSION}

It was the objective of our study to investigate the impact of MPCs on LUTS, as the clinical significance of MPCs in the urological outpatient setting is unclear, even though urologists have believed that most of MPCs are asymptomatic. Our study did not show any significant difference in LUTS parameters (IPSS and bother score) according to the presence of MPCs.

Dik et al. evaluated 704 TRUS findings, and found 34 (5\%) MPCs. The authors reported that 32\% of the patients with MPC had impaired micturition. ${ }^{1}$ Coppens at al. enrolled 65 patients with MPCs retrospectively, and found that $25 \%$ of the patients demonstrated LUTS. ${ }^{17}$ Zhang and associates reported that 10 (67\%) out of 15 MPC patients that were enrolled showed prostatitis-

like symptoms. ${ }^{13}$ However, the purpose of all above studies was to address the impact of endourological intervention of MPCs, and still there have been no case-control studies thus far to our best knowledge. Most of the articles regarding MPCs in the literature are case reports that

This article is protected by copyright. All rights reserved. 
have shown the impact of therapeutic procedures on symptomatic MPCs. Interestingly, case reports show that most of the MPCs that caused symptoms such as LUTS or urinary retention were anatomically projecting to the bladder outlet and subsequently caused outlet obstruction. ${ }^{8,}$ ${ }^{18-26}$ Radiographically, they were shown on transabdominal ultrasound as protruding cystic masses originating in the prostatic urethra upward into the bladder neck. Of the 606 patients who underwent TRUS in our study, there were no cases of MPCs protruding into the bladder neck, and this could be one of the reasons why the MPCs in our study were not significantly more symptomatic than no MPCs.

Table 3 shows the size distribution of the MPCs in our cohort. As there were large MPCs with more than $10 \mathrm{~cm}$ in transverse diameter, we assessed if the size of the MPCs correlated with the symptom score among the patients with MPCs, but we failed to obtain any linear correlation between the size of MPCs and the LUTS symptom score. As many of the case reports suggest, anatomical location rather than the size of the MPCs might be an important factor to predict LUTS, and this should be considered in a future study.

Cysts can occur in any organs in the human body and they are commonly found on imaging studies such as ultrasound, computed tomography, or magnetic resonance imaging. Most of the clinical concerns that arise from cysts are regarding malignant transformation, but cysts usually do not result in clinical symptoms unless rare complications such as rupture, compression and mass effect, infection, or bleeding occurs. Skolarikos et al. reviewed about 100 articles regarding simple renal cysts, and found that only $2-4 \%$ of the cases became symptomatic due to 
enlargement or complications such as hemorrhage, infection, or rupture. ${ }^{27}$ Another body organ where cysts are commonly detected is the liver. A review article by Mavilia et al. described that $15-16 \%$ of hepatic cysts can become symptomatic with causing abdominal pain, early satiety, nausea, or vomiting, but it depends on the size and the growth of the cysts. ${ }^{28}$ Likewise, in the prostate, based on the results of our study, the presence of MPCs alone does not predict the development of moderate to severe LUTS, and this can suggest that it might be rare that MPCs become symptomatic.

It is not surprising that our multivariate analysis shows age and prostate size are independent predictors of moderate to severe LUTS. Interestingly, history of DM and concurrent urological medications can predict moderate/severe LUTS. This can be explained that more patients with moderate to severe LUTS were taking urological medications such as alpha-blockers, 5-alpha reductase inhibitors, or antimuscarinics. Regarding the association between DM and LUTS, there have been several studies that showed association of Type 2 DM and LUTS. ${ }^{29-31}$ This should be further investigated in the future.

Out study has several limitations that should be discussed. Given its retrospective nature, there has been no randomization, raising a risk of selection bias. Another important limitation is that there was significant difference between the MPC and no MPC groups, given no randomization. As seen in Table 1, the group without MPCs had higher age, more diabetic history, were taking more urological medications (which was an independent predictor of moderate to severe LUTS), and had more storage symptoms. This significant difference might have affected the results of 
our study that MPCs did not affect significantly on the LUTS parameters. However, the presence of MPCs still was not an independent predictor for moderate to severe LUTS, even after we adjusted other significant factors in the multivariate model, therefore the conclusion of our study can still be justified. One very critical point in our study is that we didn’t measure the sagittal diameter of the cysts in delineating the burden of MPCs. Given 3-dimensional nature of the cysts, we should have measured the volume of the cysts instead of measuring transverse diameter only, and this could have affected our study result. Another important point is that we only analyzed the sum of total, storage, and voiding IPSS without sub-analyzing each component of IPSS (frequency, nocturia, urgency, etc) as exampled in a study by Lee at al. ${ }^{32}$ Given the significant difference in storage IPSS between the MPC and no MPC groups (Table 1), this sub-analysis would have provided further insight in association of MPC and LUTS. Other relevant point in our study is that we didn’t analyze the association of MPCs and prostatic surgery, which could be a future investigation.

In conclusion, our study showed that the presence of MPCs does not independently predict moderate to severe LUTS. Therefore, it is generally thought that MPCs themselves are less likely to become symptomatic, unless there are specific anatomical variations such as bladder outlet obstruction seen in numerous case reports. Even though our study failed to demonstrate any positive associations, it is believed that our study has its own meaningfulness in that this is potentially the first large retrospective case-control study to our best knowledge to address the association between MPCs and LUTS. Further prospective randomized trial will be needed for 
better clarification.

This article is protected by copyright. All rights reserved. 


\section{ACKNOWLEDGEMENTS}

This study did not receive any specific funding.

This article is protected by copyright. All rights reserved. 


\section{DISCLOSURE}

The authors declare no conflict of interest.

This article is protected by copyright. All rights reserved. 


\section{REFERENCES}

1. Dik P, Lock TM, Schrier BP, ZeijlemakerBY, Boon TA. Transurethral marsupialization of a medial prostatic cyst in patients with prostatitis-like symptoms. J Urol. 1996;155:13011304.

2. Ishikawa M, Okabe H, Oya T, et al. Midline prostatic cysts in healthy men: incidence and transabdominal sonographic findings. AJR Am J Roentgenol. 2003;181:1669-1672.

3. Kato H, Komiyama I, Maejima T, et al. Histopathological study of the müllerian duct remnant: clarification of disease categories and terminology. J Urol. 2002;167:133-136.

4. Soto AJ, Subira NR, Manasia P, et al. Classification of cystic structures located at the midline of the prostate: our experience. Arch Ital Urol Androl. 2004;76:75-79.

This article is protected by copyright. All rights reserved. 
5. Kato H, Hayama M, Furuya S, et al. Anatomical and histological studies of so-called Müllerian duct cyst. Int J Urol. 2005;12:465-468.

6. Furuya R, Furuya S, Kato H, et al. New classification of midline cysts of the prostate in adults via a transrectal ultrasonography-guided opacification and dye-injection study. BJU Int. 2008;102:475-478.

7. Shebel HM, Farg HM, Kolokythas O, et al. Cysts of the lower male genitourinary tract: embryologic and anatomic considerations and differential diagnosis. Radiographics. 2013;33:1125-1143.

8. Lee JY, Kang DH, Park HY, et al. An anteriorly positioned midline prostatic cyst resulting in lower urinary tract symptoms. Int Neurourol J. 2010;14:125-129.

9. Sheu JY, Yin JH, Tung MC. Midline prostatic cyst in a young man with difficult voiding. Incont Pelvic Floor Dysfunct. 2012;6:112-114.

10. Saha B, Sinha RK, Mukherjee S, et al. Midline prostatic cyst in a young man with lower urinary tract symptoms. BMJ Case Rep. 2014; pii: bcr2014207816. doi: 10.1136/bcr2014-207816.

11. Gürağaç A, Demirer Z, Alp BF, Aydur E. Severe lower urinary tract symptoms due to anteriorly located midline prostatic cyst arising from the bladder neck in a young male: case report. Sao Paulo Med J. 2016;0: doi: 10.1590/1516-3180.2016.0056280516.

12. Nakano K, Kiuchi H, Miyagawa Y, Tsujimura A, Nonomura N. Midline cyst of the prostate with increased urinary frequency and urgency: a case report. Hinyokika Kiyo.

This article is protected by copyright. All rights reserved. 
2018;64:71-74.

13. Zhang HH, Qi F, Wang J, Chen MF, Li Z, Zu XB. Midline prostatic cysts presenting with chronic prostatitis or secondary infertility and minimally invasive treatment: endoscopic or laparoscopic approach? Surg Sci. 2011;2:285-289.

14. Barry MJ, Fowler FJ Jr, O'Leary MP, et al. The American Urological Association symptom index for benign prostatic hyperplasia. The Measurement Committee of the American Urological Association. J Urol. 1992;148:1549-1557.

15. McVary KT, Roehrborn CG, Avins AL, et al. Update on AUA guideline on the management of benign prostatic hyperplasia. J Urol. 2011;185:1793-1803.

16. Gratzke C, Bachmann A, Descazeaud A, et al. EAU Guidelines on the Assessment of Non-neurogenic Male Lower Urinary Tract Symptoms including Benign Prostatic Obstruction. Eur Urol. 2015;67:1099-1109.

17. Coppens L, Bonnet P, Andrianne R, de Leval J. Adult müllerian duct or utricle cyst: clinical significance and therapeutic management of 65 cases. J Urol. 2002;167:17401744.

18. Zhu JP, Meyhoff HH. Prostatic cyst. An unusual but important finding in male urogenital dysfunction. Scand J Urol Nephrol. 1995;29:345-349.

19. Ng KJ, Milroy EJ, Rickards D. Intraprostatic cyst—a cause of bladder outflow obstruction. J R Soc Med. 1996;89:708-709.

20. Barzilai M, Ginesin Y. A müllerian prostatic protruding into the base of the urinary

This article is protected by copyright. All rights reserved. 
bladder. Urol Int. 1998;60:194-196.

21. Chang SG, Hwang IC, Lee JH, Park YK, Lim JW. Infravesical obstruction due to benign intraurethral prostatic cyst. J Korean Med Sci. 2003;18:125-126.

22. Yildirim I, Kibar Y, Sümer F, Bedir S, Deveci S, Peker AF. Intraurethral prostatic cyst: a rare cause of infravesical obstruction. Int Urol Nephrol. 2003;35:355-356.

23. Tambo M, Okegawa T, Nutahara K, Higashihara E. Prostatic cyst arising around the bladder neck-cause of bladder outlet obstruction: two case reports. Hinyokika Kiyo. 2007;53:401-404.

24. Nayyar R, Dogra PN. Anteriorly placed midline intraprostatic cyst. J Endourol. 2009;23:595-597.

25. Shirakawa H, Kozakai N, Sugiura H, Hara S. Prostatic retention cyst around the bladder neck: a case report. Hinyokika Kiyo. 2009;55:583-586.

26. Al-Nasser KA, Almannie RM. New technique for the management of anteriorly located midline prostatic cysts causing severe lower urinary tract symptoms: Case report and literature review. Int J Surg Case Rep. 2019;55:107-111.

27. Skolarikos A, Laguna MP, de la Rosette JJ. Conservative and radiological management of simple renal cysts: a comprehensive review. BJU Int. 2012;110:170-178.

28. Mavilia MG, Pakala T, Molina M, Wu GY. Differentiating cystic liver lesions: A review of imaging modalities, diagnosis and management. J Clin Transl Hepatol. 2018;6:208216.

This article is protected by copyright. All rights reserved. 
29. Van Den Eeden SK, Ferrara A, Shan J, et al. Impact of type 2 diabetes on lower urinary tract symptoms in men: a cohort study. BMC Urol. 2013;13:12.

30. Tam CA, Helfand BT, Erickson BA. The Relationship Between Diabetes, Diabetes Severity, Diabetes Biomarkers, and the Presence of Lower Urinary Tract Symptoms: Findings From the National Health and Nutrition Examination Survey. Urology. 2017;105:141-148.

31. Galì A, Mucciardi G, Butticè S, et al. Correlation Between Advanced Glycation EndProducts, Lower Urinary Tract Symptoms and Bladder Dysfunctions in Patients with type 2 Diabetes Mellitus. Low Urin Tract Symptoms. 2017;9:15-20.

32. Lee WC, Wu CC, Wu HP, Tai TY. Lower urinary tract symptoms and uroflowmetry in women with type 2 diabetes mellitus with and without bladder dysfunction. Urology. 2007;69:685-690.

This article is protected by copyright. All rights reserved. 


\section{FIGURE LEGENDS}

Figure 1. Examples of measuring the transverse diameter of the cysts for large (A), small (B), and tiny (C) midline prostatic cysts.

This article is protected by copyright. All rights reserved. 
Table 1. Comparison of clinical variables between the two groups

\begin{tabular}{|c|c|c|c|}
\hline & $\begin{array}{l}\text { No MPCs } \\
(\mathrm{n}=407)\end{array}$ & $\begin{array}{l}\text { MPCs } \\
(n=199)\end{array}$ & $P$ Value \\
\hline Mean age, years & $58.92 \pm 12.53$ & $56.69 \pm 12.05$ & $0.038^{\mathrm{a}}$ \\
\hline Mean BMI, kg/m² & $23.67 \pm 4.22$ & $24.08 \pm 3.35$ & $0.233^{\mathrm{a}}$ \\
\hline History of DM (\%) & $87(21.4)$ & $26(13.1)$ & $0.014^{\mathrm{b}}$ \\
\hline Medications (\%) ${ }^{\mathrm{c}}$ & $53(13.0)$ & $12(6.0)$ & $0.008^{b}$ \\
\hline Total IPSS & $14.17 \pm 8.87$ & $12.71 \pm 9.16$ & $0.060^{\mathrm{a}}$ \\
\hline Storage IPSS & $5.60 \pm 3.79$ & $4.80 \pm 3.84$ & $0.016^{\mathrm{a}}$ \\
\hline Voiding IPSS & $8.55 \pm 6.06$ & $7.83 \pm 6.07$ & $0.169^{\mathrm{a}}$ \\
\hline Bother score & $3.22 \pm 1.60$ & $2.98 \pm 1.64$ & $0.088^{\mathrm{a}}$ \\
\hline Mean total PSA, ng/ml & $3.58 \pm 26.67$ & $2.48 \pm 9.58$ & $0.574^{\mathrm{a}}$ \\
\hline Mean prostate size, $\mathrm{ml}$ & $26.16 \pm 9.81$ & $26.17 \pm 9.62$ & $0.990^{\mathrm{a}}$ \\
\hline \multicolumn{4}{|c|}{ MPC, midline prostatic cyst; BMI, body mass index; DM, diabetes mellitus; IPSS, international } \\
\hline \multicolumn{4}{|c|}{ a Independent t-test; ${ }^{\text {b} F i s h e r ' s ~ e x a c t ~ t e s t ; ~ ' ~ C o n c u r r e n t ~ u r o l o g i c a l ~ m e d i c a t i o n s ~ a f f e c t i n g ~ v o i d i n g ~}$} \\
\hline
\end{tabular}

This article is protected by copyright. All rights reserved. 
Table 2. Univariate and multivariate analysis of variables to predict independent factors for moderate/severe lower urinary tract symptoms

\begin{tabular}{lcc}
\hline & Univariate OR $(95 \% \text { CI })^{\mathrm{a}}$ & Multivariate OR (95\% CI) $^{\mathrm{a}}$ \\
\hline Age & $1.056(1.040-1.073)$ & $1.040(1.022-1.058)$ \\
BMI & $0.968(0.922-1.016)$ & $0.966(0.918-1.016)$ \\
History of DM & $2.713(1.567-4.699)$ & $1.887(1.057-3.368)$ \\
Medications & $5.593(2.207-14.178)$ & $3.386(1.298-8.833)$ \\
PSA & $1.048(0.993-1.106)$ & $1.005(0.983-1.027)$ \\
Prostate size & $1.049(1.026-1.072)$ & $1.029(1.004-1.055)$ \\
Presence of MPC & $0.730(0.506-1.053)$ & $0.839(0.568-1.240)$
\end{tabular}

OR, odds ratio; CI, confidence interval; BMI, body mass index; DM, diabetes mellitus; PSA, prostate-specific antigen; MPC, midline prostatic cyst.

${ }^{\mathrm{a} B i n a r y}$ logistic regression test; ${ }^{\mathrm{b}}$ Concurrent urological medications affecting voiding condition such as alpha-blockers, 5-alpha reductase inhibitors, and antimuscarinics.

This article is protected by copyright. All rights reserved. 
Table 3. Size distribution of the midline prostatic cysts

\begin{tabular}{lc}
\hline Size (cm) & Number (\%) \\
\hline 1.9 or below & 47 \\
$2.0-2.9$ & 43 \\
$3.0-3.9$ & 31 \\
$4.0-4.9$ & 29 \\
$5.0-5.9$ & 16 \\
$6.0-6.9$ & 11 \\
$7.0-7.9$ & 12 \\
$8.0-8.9$ & 1 \\
$9.0-9.9$ & 4 \\
10.0 or above & 5 \\
\hline
\end{tabular}

This article is protected by copyright. All rights reserved. 

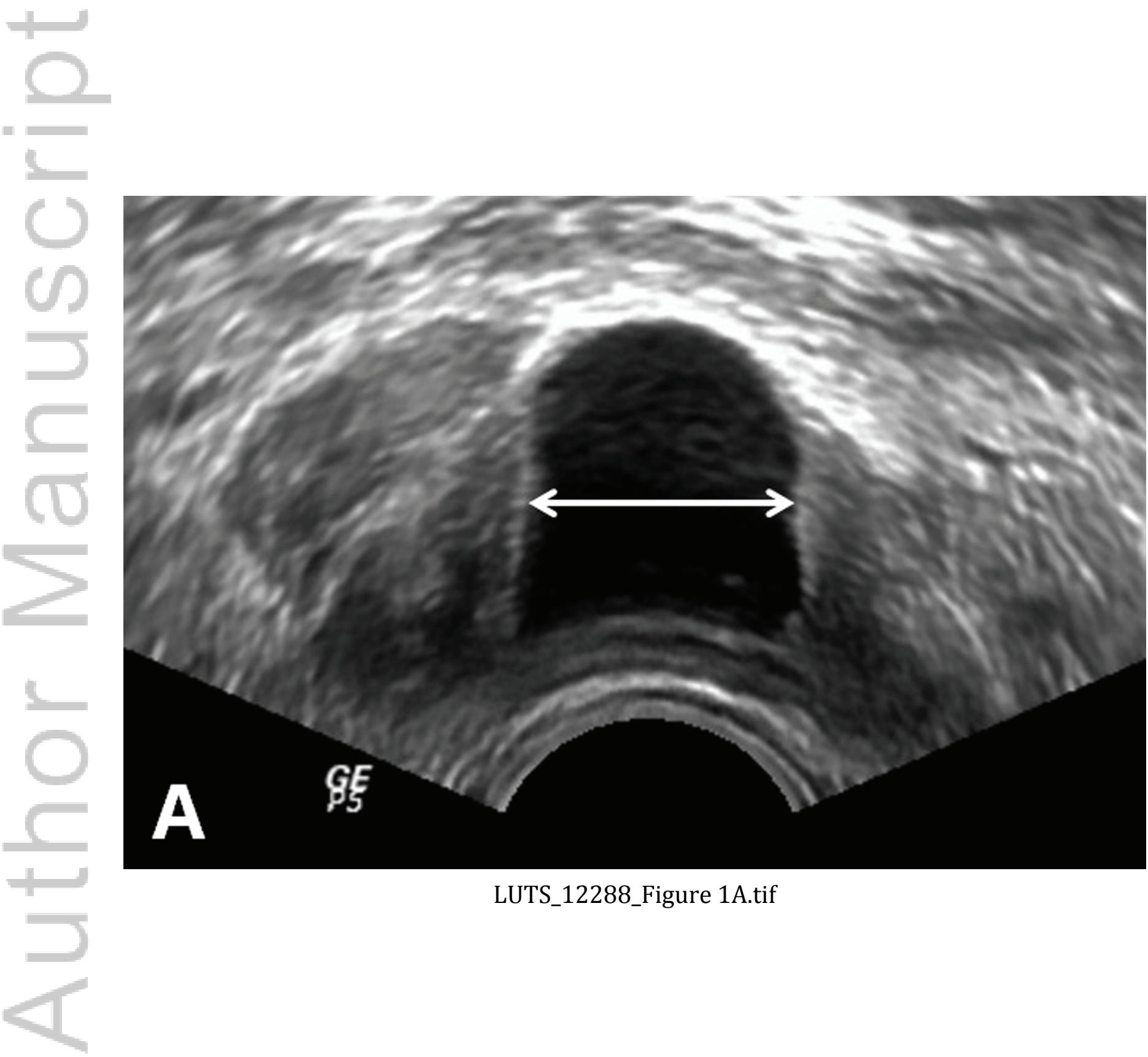

LUTS_12288_Figure 1A.tif

This article is protected by copyright. All rights reserved. 


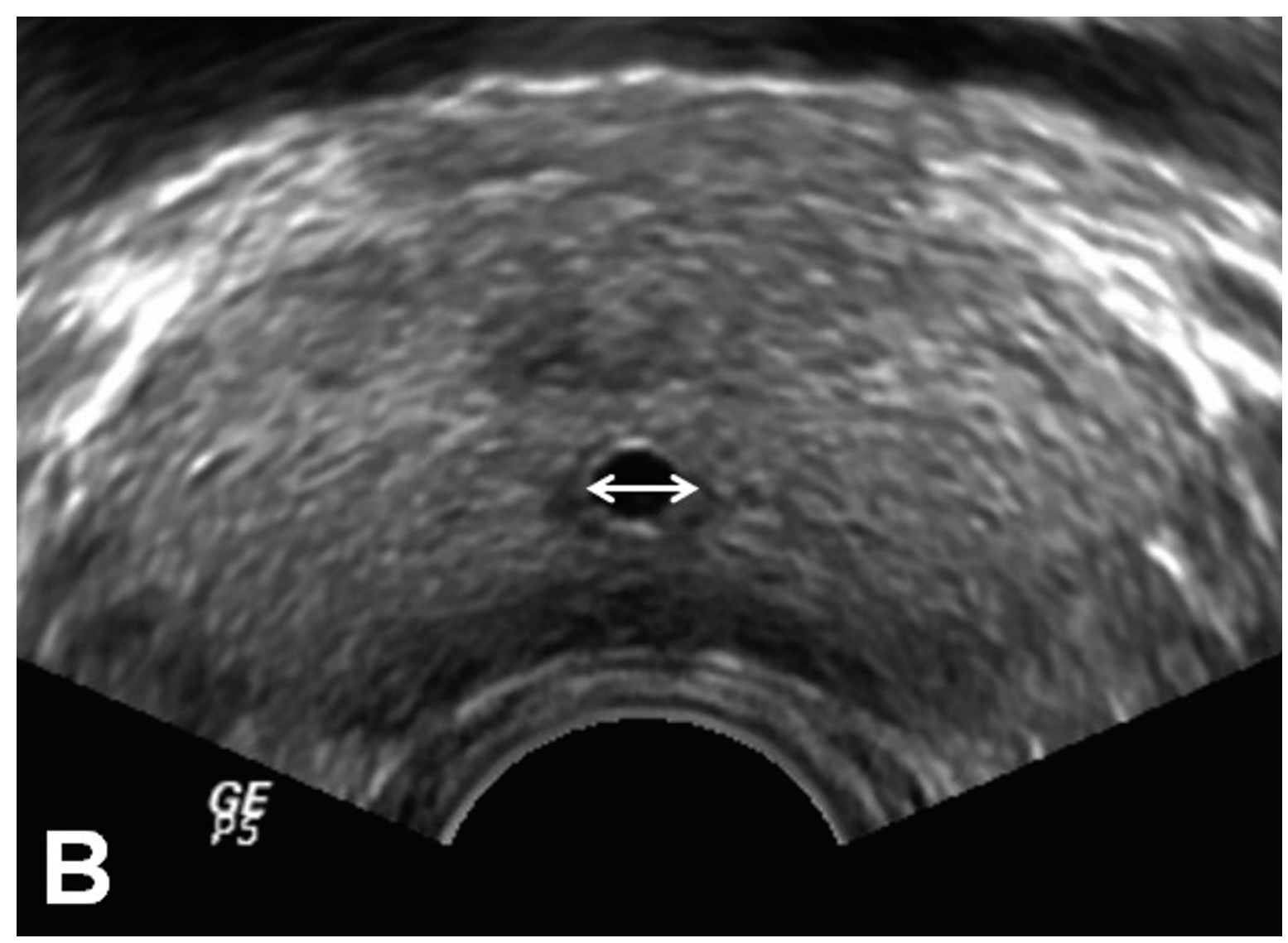

LUTS_12288_Figure 1B.tif

This article is protected by copyright. All rights reserved. 


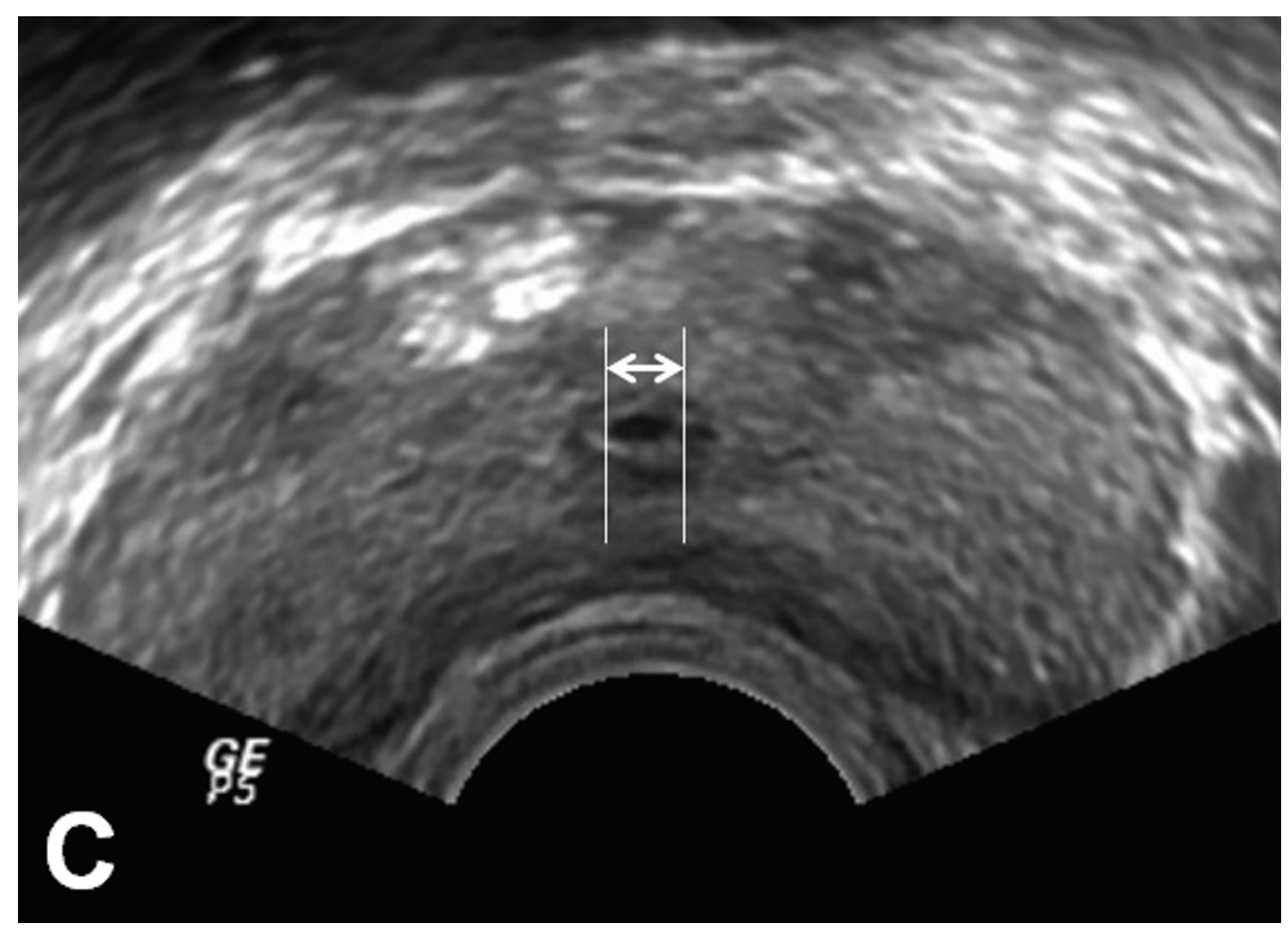

LUTS_12288_Figure 1C.tif

This article is protected by copyright. All rights reserved. 